\title{
Farewell to the founder of Infection, Walter Marget
}

\section{J. R. Bogner}

Published online: 7 March 2013

(C) Springer-Verlag Berlin Heidelberg 2013

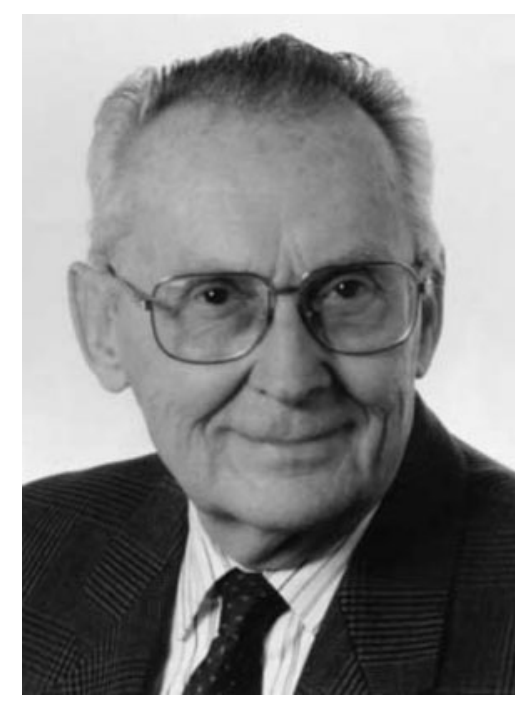

In 1973, Professor Walter Marget founded a new journal that was explicitly devised to be a scientific forum for the practice of infectious diseases as defined from a clinical aspect, starting at symptoms and signs of diseases, diagnostic techniques including clinical microbiology, pathogenesis and mechanisms of disease as well as the development and implementation of new therapeutic approaches and antiinfective compounds.

In the editorial to the first issue, he wrote "... the concern of the Editors, however, is, basing their considerations

\section{J. R. Bogner ( $\square)$}

Sektion Klinische Infektiologie, Klinik und Poliklinik IV, Klinikum der Universität München, Pettenkoferstr. 8a, 80336 Munich, Germany

e-mail: Johannes.Bogner@med.uni-muenchen.de on the clinician, to present in this journal current observations, findings and knowledge from a clinical point of view..." [1].

On 21 January 2013, Professor Marget died at the age of 92. He was Editor in Chief from 1973 to 1999 and, thereafter, he continued to participate as Senior Editor. After the editorial team was restructured in 2012, Walter Marget still consented to be with the Journal as Editor Emeritus.

In several conversations during the year 2012, he accepted my promise to lead the Journal in the spirit of its original mission as a journal of clinical infectious diseases. The intention to bring basic science and clinical care for the patient together resulted in the format of Infection and will remain as such in remembrance of the great personality of its founder, Walter Marget. His vision was that "it appeared advisable .... to introduce a journal which serves the whole of Europe in order to draw qualified studies from over a wider area and to promote communication" [1]. Finally, Infection became an international journal that has a scientific impact on readers all over the world including authors, readers, and reviewers in North America despite the presence of other highly reputed journals there.

Walter Marget was a person with a wealth of attributes which predisposed him to be successful as an editor: he had both humor and seriousness, warmth and distance if necessary, microbiological skills and the view of the clinician, and he had widespread collegial connections which allowed him to set up the international stage for Infection. Taken together he had the "culture and sensitivity" in the double meaning that is the hallmark of an infectious disease person, as originally propagated by Maxwell Finland in the way he defined an infectious disease person's attributes in specialization and professionalism.

Walter Marget is not only the founder of Infection. He was a successful scientist and teacher and he was followed 
by a number of great personalities who took his advice and leadership as the head of the Infectious Disease Unit at the Children's Hospital of the University of Munich. His name is linked to the Walter Marget scholarships which enabled young clinicians and scientists to be trained abroad during a time when Infectious Disease training was not offered in Germany. Moreover, Walter Marget founded a yearly symposium on antiinfective chemotherapy-the "Walter Marget Chemotherapiegespräch". And as Christian Ruef, his successor as Editor in Chief put it: "younger colleagues may look at Walter Marget as a role model. It may be well worthwhile to try to follow his example, since his way of mixing retirement with professional activities seems to have kept him young" [2]. We also appreciate his activities as a founding member of the German Infectious Disease Society (DGI), for which Infection is, among others, also the scientific publication organ of the DGI.

Munich, February 2013

Johannes R. Bogner

Conflict of interest None.

\section{References}

1. Margret W. Editor's note. Infection. 1973;1:1-3.

2. Ruef C. Happy birthday Walter Marget. Infection. 2000;28:199. 